\title{
Intergenerational Transfers in the New Dutch Pension Contract
}

\author{
Servaas van Bilsen ${ }^{1}$ D $\cdot$ Roel J. Mehlkopf ${ }^{2} \cdot$ Stephan van Stalborch $^{3}$
}

Accepted: 9 January 2022 / Published online: 15 February 2022

(c) The Author(s) 2022

\begin{abstract}
This paper measures intergenerational transfers through the solidarity reserve of the newly proposed Dutch occupational pension contract. Our first conclusion is that the role of the solidarity reserve is higher than it may appear at a first glance. The fraction of pension savings that can go directly into the solidarity reserve is limited to $10 \%$. However, we find that, in addition, around $30 \%$ of the pension savings of a young worker can subsequently be transferred to the solidarity reserve via a levy on future positive excess returns. Our second finding is that the solidarity reserve can introduce a substantial pay-as-you-go element within a funded pension scheme. This feature of the solidarity reserve can be overlooked easily and is not mentioned in the pension bill. Our policy recommendation to pension funds is to make explicit whether or not there is a pay-as-you-go element via the solidarity reserve, and if so to assess whether this is desirable.
\end{abstract}

Keywords Funded pension schemes $\cdot$ Solidarity reserve $\cdot$ Intergenerational transfers

JEL Classification G12 · G18 · G23 · H68

Servaas van Bilsen

S.vanBilsen@uva.nl

Roel J. Mehlkopf

R.J.Mehlkopf@tilburguniversity.edu

Stephan van Stalborch

S.M.van.Stalborch@dnb.nl

1 University of Amsterdam and NETSPAR, PO Box 15867, 1001 NJ Amsterdam,

The Netherlands

2 Tilburg University NETSPAR and Cardano, Tilburg, The Netherlands

3 De Nederlandsche Bank, Amsterdam, The Netherlands 


\section{Introduction}

In December 2020, the Dutch government published a pension bill which sets out the main features of a reform of Dutch occupational pensions. The proposed reform includes a new fiscal framework for Dutch occupational pensions and a new pension contract. This new pension contract is expected to replace many of the current defined benefit contracts in the Netherlands. Defined benefit pensions are the dominant contracts in the Netherlands, but have been under pressure during the past decade as a result of e.g. underfunding and discussions on intergenerational fairness between young and old generations (see e.g. Bovenberg et al., 2016; Bovenberg \& Nijman, 2018).

The pension bill aims to structurally overcome the problems of the current defined benefit contracts by introducing a new contract type, simply referred to as the new pension contract. A key characteristic of the new pension contract is that it does not include pension liabilities: participants do not accumulate pension entitlements. Instead, participants acquire a personal pension wealth, which is a personal 'share' in a collective pool of assets. This feature has similarities with defined contribution contracts, in which participants also acquire a personal pension wealth. ${ }^{1}$

A feature of the new pension contract is that part of the pension fund assets is not allocated to anyone. This wealth is referred to as the solidarity reserve, and can be used for wealth transfers between generations. The conceptual idea behind these intergenerational transfers is that these can facilitate intergenerational risk sharing which can potentially lead to welfare gains from an ex-ante perspective (see e.g. Gordon \& Varian, 1988; Ball \& Mankiw, 2007; Gollier, 2008).

The government imposes legislative boundaries on the use of the solidarity reserve. In particular, the pension bill sets limitations on the size of the solidarity reserve. A negative solidarity reserve is not allowed, and the maximum size of the reserve is limited to $15 \%$ of total pension fund assets. Also, the bill imposes constraints on the mechanisms that govern the inflows and outflows of the solidarity reserve. The pension bill states that there are only two ways to fill the solidarity reserve: via a levy on pension contributions of workers and via a levy on positive collective excess returns. Both the levy on contributions and the levy on positive collective excess returns are limited to $10 \%$. The specific design of the new pension contract causes wealth transfers between generations. The central topic of this paper is to explore the sizes of these transfers.

The motivation of the government to impose legislative boundaries is that this limits ex-post redistribution between generations and thereby reduces discontinuity risk, see e.g. Bovenberg and Mehlkopf (2014). At the same time, the legislative constraints can prevent pension funds from being able to implement a firstbest risk sharing solution. Indeed, the first-best risk sharing solutions (in absence of discontinuity risk) in e.g. Gollier (2008) are not feasible as this requires much larger risk sharing transfers across generations than is possible within the

\footnotetext{
1 See Metselaar et al. (2022) for a more elaborate description of the new pension contract.
} 
legislative boundaries. Hence, the risk sharing solutions via the solidarity reserve will typically be second-best risk sharing solutions.

This paper is not concerned with efficiency: we do not derive first-best risk sharing solutions, nor do we consider second-best risk sharing solutions within the legislative boundaries of the solidarity reserve. These aspects are already considered in two other papers in this special issue: see Werker and Muns (2022) on first-best risk sharing solutions and Metselaar et al. (2022) for second-best solutions within legislative boundaries. Also Van Bilsen et al. (2021) study the characteristics of the optimal policy settings for the solidarity reserve and its welfare effects.

Instead, our paper focuses on the intergenerational transfers and redistribution that result from de solidarity reserve. In doing so, we take the design of the policy for the solidarity reserve as given by CPB (2020a, b), which is the research conducted on behalf of the government. In other words: we consider the policy designs that the government has put forward as examples, and we are not concerned with the question to what extent these policy designs are efficient.

Our first key finding is that the role of the solidarity reserve is higher than it appears at a first glance. At a first glance, one may be tempted to say that the redistributive effects of the solidarity reserve are limited. After all, since at least $90 \%$ of pension contributions goes into a personal pension account, one could be tempted to say that the new pension contract is at least $90 \%$ 'personal' and up to $10 \%$ 'collective'. However, this conclusion is too short-sighted. The accrued personal pension wealth of a participant is not fully personal, because also up to $10 \%$ of future positive collective excess returns can go into the solidarity reserve. The part of the collective excess return that goes into the solidarity reserve is thus not allocated to personal pension wealth levels. To assess the extent to which the pension contract is personal in nature and to what extent it is not, we define the term 'Solidarity Tax'. This term is defined as the share of the pension contributions, paid at a certain age, that is channeled into the solidarity reserve. The Solidarity Tax accounts for both direct and subsequent transfers into the solidarity reserve. Direct transfers occur at the moment of saving, as a result of a levy on pension contributions. Subsequent transfers occur as a result of a levy on future positive collective excess returns. In other words: for every 100 euro that is paid into the new pension contract at a certain age, the Solidarity Tax tracks how many of these euros are channeled into the solidarity reserve either directly or at a later point in time. The term Solidarity Tax is adopted from CPB (2020a) and may be of high policy relevance.

It is important to note that the Solidarity Tax only tracks inflows into the solidarity reserve, and does not account for future outflows received back from the solidarity reserve. Hence, the Solidarity Tax does not measure the net value of total transfers (inflows and outflows) and hence does not tell anything about incentives for participants to contribute less or more to the pension fund. Also, the Solidarity Tax does not measure redistribution or intergenerational fairness (for this purpose, we will later define Net Value Transfer). In this context, one could interpret the Solidarity Tax as a worst-case measure: how much value does a generation contribute to the solidarity reserve in case this generation will not receive any payout from the reserve? 
For our benchmark setting, based on the government pension bill, we calculate that the Solidarity Tax equals approximately $40 \%$ of pension savings for young workers. The fraction of pension savings that goes directly into the solidarity reserve is equal to $10 \%$, and, in addition, around $30 \%$ of the pension savings of the young worker is transferred to the solidarity reserve at a later point in time via a levy on the future positive collective excess returns. The Solidarity Tax decreases with age over the working period, and declines to around $15 \%$ for retired workers. The Solidarity Tax is insensitive to the current size of the solidarity reserve, ${ }^{2}$ but is sensitive to the collective investment strategy and the allocation rule for collective excess returns.

If a pension fund wants to reduce the Solidarity Tax, we find that an effective approach is to use an alternative design of the solidarity reserve. In this alternative approach, a pension fund transfers part of the collective excess returns to the solidarity reserve only if the average past (instead of current) collective excess return is positive. This alternative design leads to a substantially lower Solidarity Tax. For young participants, aged 25, the Solidarity Tax reduces from 40 to $20 \%$. For a 45-year old worker, the Solidarity Tax reduces from 25 to $15 \%$. The intuition behind this alternative design is that a positive excess return in one single year may not be a desirable measure, because a positive excess return may be preceded by negative excess returns in previous years. In addition, the alternative measure reduces transfers into the reserve in scenarios in which bad and good times alternate. In such scenarios, the alternative measure features limited transfers into the reserve as the average past returns can be moderate (while annual returns can be large). This alternative measure is somewhat similar to the concept of a 'high watermark' in performance measurement of fund managers, see e.g. Liang (1999).

Our second key finding is that the solidarity reserve can introduce a pay-as-yougo element within a funded pension scheme. Indeed, the introduction of the solidarity reserve creates a possibility for pension funds to directly or indirectly transfer pension wealth from one generation to another generation. As a result, the solidarity reserve can mimic certain properties of pay-as-you-go financed schemes. A pay-asyou-go element can, for example, arise if the solidarity reserve is primarily filled by working generations while it is primarily paid out to retired generations.

In order to assess whether and to what extent the solidarity reserve leads to a payas-you-go element in the new pension contract, we introduce the Net Value Transfer of a generation. This is defined as the difference between the ex-ante market value of all wealth paid into the solidarity reserve over the remaining life-cycle of a specific generation and the ex-ante market value of all wealth received from the solidarity reserve over the remaining life-cycle of that same generation. We express the Net Value Transfer as a percentage of the ex-ante market value of total pension income over the remaining life-cycle. Hence, if the Net Value Transfer equals $10 \%$ for a certain generation, then $10 \%$ of the market value of future pension income of this generation is transferred to other generations.

\footnotetext{
${ }^{2}$ Note that this conclusion depends on the contribution policy. If individuals contribute more in case of a high solidarity reserve, the Solidarity Tax will be sensitive to the current size of the solidarity reserve.
} 
We find that, in the example policy designs featured in CPB (2020b), the solidarity reserve can introduce substantial value transfers between generations. In the payout policy in which every year $1 / 15$ th of the reserve is being paid out, we find that a value transfer from young to old generations arises. Intuitively, older generations have accumulated relatively high pension wealth and therefore receive relatively high transfers during their remaining lifetime as the reserve pays out $1 / 15$ th every year. This 'initial gift' to the initial old generations has to be financed by younger and future generations because the pension contract is a zero-sum game between generations. In case we consider a policy design in which the reserve aims to ensure a certain minimum replacement ratio for retirees, we find that the sizes of the intergenerational transfers are very sensitive to the level of the minimum replacement ratio.

The possibility of a pay-as-you-go element via the solidarity reserve is remarkable from a policy perspective. The pension bill devotes a lot of attention towards the removal of a pay-as-you-go element in the current pension contracts resulting from the so-called system of uniform contribution rates and uniform accrual rates. ${ }^{3}$ Given the explicit aim of the policy reform to remove a pay-as-you-go element in the current funded pension system, it is remarkable that the proposals of the government allow for the introduction of a new pay-as-you-go element in Dutch pension contracts via the solidarity reserve. This feature of the solidarity reserve can be overlooked easily and is not mentioned in the pension bill, while it has a high policy relevance. Our recommendation to pension funds is therefore to make explicit whether or not there is a pay-as-you-go element via the solidarity reserve by calculating the Net Value Transfer for all generations. If there is a pay-as-you-element, we recommend to assess whether or not this is desirable. If a pay-as-you-go element is considered undesirable, then a pension fund should re-evaluate the design of the solidarity reserve.

The market value of the stochastic cashflows in the new pension contract is not immediately clear, since collective positive excess returns will only be partially added to individual investment accounts-which is a common feature of pension and life insurance policies (see e.g Grosen and Jørgensen, 2000). We apply a valuebased approach to determine the market value of the stochastic cashflows of the new pension contract. This approach is essentially an application of embedded option pricing in financial products. In a value-based approach, the outcomes of a pension policy can be replicated with financial products such as derivatives (see e.g. Ponds, 2003). For example, a minimum guarantee in a pension product can be replicated with a long position in a put option. Indeed, in bad weather scenarios, the holder of a long put makes a profit. And a levy on positive returns can be replicated with a short

\footnotetext{
3 See e.g. Bovenberg et al. (2016). The accrual rate is the same for all workers irrespective of age. This so-called uniform accrual rate implies that benefits are backloaded, because the time value of money implies that the value of the (deferred) annuity (as a percentage of the wage) rises with age. Despite this backloading of benefit accrual, industry funds charge the same contribution rate irrespective of age. This combination of uniform (i.e. age-independent) accrual rates and uniform contribution rates implies that firms with a younger workforce typically subsidize firms with an older workforce in the same sector. Hence, Dutch funded pension systems include an implicit pay-as-you-go element.
} 
position in a call option. Indeed, in good weather scenarios, the holder of a short call makes a loss. In our paper, we apply this approach to our results. We find that the degree of non-linearity imposed by the solidarity reserve on outcomes is quite weak, and hence the solidarity reserve is not able to generate outcomes that mimic the payouts of a long put or short call. The main reason for this is the limited size of the solidarity reserve. If setbacks are large, the solidarity reserve becomes depleted quite fast and minimum replacement ratios cannot be protected. And if windfalls are large, then the maximum size of the solidarity reserve is reached quite fast so that positive excess returns fully accrue to individual members. We show that the solidarity reserve is unable to impose a pronounced non-linear structure on pension outcomes in case the reserve pays out $1 / 15$ th every year. If the policy aims to ensure a minimum replacement ratio of $50 \%$, then we find a more pronounced non-linear structure on pension outcomes.

Our findings on Net Value Transfers are an application of generational accounting in funded pension schemes, see e.g. Draper et al. (2014). Both studies apply generational accounting to Dutch occupational pension schemes in a stochastic framework using standard asset pricing theory, also referred to as value-based generational accounting. The methodology offers an objective framework which provides insight into the intergenerational effects of pension contracts and pension reforms, and can help to reassure that there is no unintentional redistribution between generations. Generational accounting is more widely known for its deterministic applications in the context of long-term fiscal analysis to assess the sustainability of government finances and to measure the fiscal burdens facing current and future generations (see e.g. Auerbach et al., 1991; Kotlikoff, 1992).

\section{New Pension Contract and Financial Market}

\subsection{Description of New Pension Contract}

We now describe the new pension contract; for a full description, see "Appendix 1". We note that we do not optimize the design of the new pension contract. ${ }^{4}$ Instead, we adopt the setting from CPB (2020a, b).

We consider a discrete time setting with time horizon $T$ which is the terminal date. The solidarity reserve at time $t$ is represented by the variable $S(t)$. We assume that our pension fund consists of $G$ generations. We use the index $g \in\{1, \ldots, G\}$ to refer to generation $g$, where $g=1$ denotes the youngest generation and $g=G$ represents the oldest generation. The index $g$ can be viewed as the age of a member at time $t$.

\footnotetext{
4 Van Bilsen et al. (2021) study the characteristics of the optimal policy settings for the solidarity reserve and its welfare effects.
} 
Let $C_{g}(t)$ and $\tau_{C}(t) \geq 0$ be the pension contribution of generation $g$ at time $t$ and the share of the pension contribution that goes into the solidarity reserve. ${ }^{5}$ The new solidarity reserve, i.e. $\widetilde{S}(t)$, is given by

$$
\widetilde{S}(t)=S(t)+\tau_{C}(t) \sum_{g=1}^{G} C_{g}(t) .
$$

Generations also receive a payout from the solidarity reserve (which will be transferred to one's personal pension wealth). The pension fund board determines how the solidarity reserve is being paid out. Let us denote by $P_{g}(t)$ the payout generation $g$ will receive from the solidarity reserve at time $t$. A possible specification of $P_{g}(t)$ will be:

$$
P_{g}(t)=\frac{1}{15} \times \frac{\widetilde{W}_{g}(t)}{\widetilde{W}(t)} \times \widetilde{S}(t)
$$

where $\widetilde{W}_{g}(t)$ denotes the pension wealth level of generation $g$ at time $t$ and $\widetilde{W}(t)=\sum_{g=1}^{G} \widetilde{W}_{g}(t)$. This specification is consistent with the benchmark specification in CPB (2020a). Intuitively, (2.2) states that in every period, 1/15th of the solidarity reserve is being paid out, where the current personal account value $\widetilde{W}_{g}(t)$ determines the size of the payout. Hence, generations with low personal pension wealth receive a relatively small payout, while generations with high personal pension wealth receive a relatively large payout.

Another possible specification of $P_{g}(t)$ will be to determine $P_{g}(t)$ such that the replacement ratio will be at least $50 \%$ for retired generations (with the restriction that the solidarity reserve cannot become negative). This means that retired generations will receive a payout from the solidarity reserve only if the replacement ratio is less than $50 \%$. Note that in this specification, working generations will never receive a payout from the solidarity reserve.

Let $W^{*}(t)$ and $S^{*}(t)$ be collective pension wealth and the solidarity reserve after all pension contributions and all payouts have been made. The pension fund invests collective pension wealth $W^{*}(t)$ and the solidarity reserve $S^{*}(t)$ in the financial market. We assume that at any any time $t \in\{0,1, \ldots, T\}$, the pension fund has access to three assets: a risk-free asset, a zero-coupon nominal bond with a fixed time to maturity and a risky stock. We find that the new collective pension wealth level, i.e. $\widehat{W}(t+1)$, and the new solidarity reserve, i.e. $\widehat{S}(t+1)$, are given by

$$
\begin{gathered}
\widehat{W}(t+1)=W^{*}(t) R_{W}(t+1), \\
\widehat{S}(t+1)=S^{*}(t) R_{W}(t+1) .
\end{gathered}
$$

Here, $R_{W}(t+1)$ denotes the gross return:

\footnotetext{
${ }^{5}$ In applications, $\tau_{C}(t)$ is often set equal to $10 \%$, with the restriction that the solidarity reserve cannot exceed $15 \%$ of total pension fund assets. In case $\tau_{C}(t)=10 \%$ is not feasible, $\tau_{C}(t)$ will be determined such that the solidarity reserve will be exactly equal to $15 \%$ of total pension fund assets.
} 


$$
R_{W}(t+1)=\pi_{B}(t) R_{B}(t+1)+\pi_{S}(t) R_{S}(t+1)+\left(1-\pi_{B}(t)-\pi_{S}(t)\right) e^{r(t)},
$$

with $R_{B}(t+1)$ and $R_{S}(t+1)$ the gross return on the bond price and the stock price, respectively, $r(t)$ the risk-free interest rate, and $\pi_{B}(t)$ and $\pi_{S}(t)$ the share of pension fund assets invested in the bond and the stock, respectively.

The pension wealth level of generation $g$ will accrue a hedge return $H_{g}(t+1)$. Hence, the new pension wealth level of generation $g$ is given by ${ }^{6}$

$$
\bar{W}_{g+1}(t+1)=W_{g}^{*}(t) H_{g}(t+1) .
$$

The hedge return $H_{g}(t+1)$ depends on the desired degree of protection against interest rate risk. In case the desired degree of interest rate protection is $100 \%$, the hedge return $H_{g}(t+1)$ corresponds to the return on a bond portfolio that exactly replicates a deferred annuity that starts to pay out at the age of retirement. This definition of hedge return is consistent with Werker and Muns (2022) and CPB (2020a, b).

We are now ready to define the excess gross return on collective pension wealth, i.e. $R_{W}^{e}(t+1)$. It is defined as follows:

$$
R_{W}^{e}(t+1) \equiv \frac{\widehat{W}(t+1)}{\sum_{g=1}^{G-1} \bar{W}_{g+1}(t+1)} .
$$

The definition of the excess gross return on collective pension wealth is consistent with CPB (2020a, b). The new pension contract allows that part of the excess return goes into the solidarity reserve.

Only if the gross excess return $R_{W}^{e}(t+1)$ is larger than one (i.e. if the net excess return $R_{W}^{e}(t+1)-1$ is positive), part of the excess return goes into the solidarity reserve. The new solidarity reserve, i.e. $S(t+1)$, will be

$$
S(t+1)=\widehat{S}(t+1)+\tau_{r}(t+1) \max \left(R_{W}^{e}(t+1)-1,0\right) \sum_{g=1}^{G-1} \bar{W}_{g+1}(t+1) .
$$

Here, $\tau_{r}(t+1) \geq 0$ models the share of pension wealth that goes into the solidarity reserve. ${ }^{7}$

The new pension contract allocates the excess return across pension wealth levels $\bar{W}_{g+1}(t+1)$, with $g \in\{1, \ldots, G-1\}$. Let us define $x_{g+1}(t+1)$ the part of the excess return that is allocated to $\bar{W}_{g+1}(t+1)$. It now follows that the the new pension wealth level of generation $g+1$, i.e. $W_{g+1}(t+1)$, is given by

\footnotetext{
${ }^{6}$ Note that generation $g$ has become generation $g+1$ at time $t+1$.

7 In applications, $\tau_{r}(t+1)$ is often set equal to $10 \%$, with the restriction that the solidarity reserve cannot exceed $15 \%$ of total pension fund assets. In case $\tau_{r}(t+1)=10 \%$ is not feasible, $\tau_{r}(t+1)$ will be determined such that the solidarity reserve will be exactly equal to $15 \%$ of total pension fund assets.
} 


$$
\begin{aligned}
W_{g+1}(t+1)= & \bar{W}_{g+1}(t+1)\left[1+x_{g+1}(t+1)\left(R_{W}^{e}(t+1)-1\right)\right. \\
& \left.-\tau_{r}(t+1) x_{g+1}(t+1) \max \left(R_{W}^{e}(t+1)-1,0\right)\right] .
\end{aligned}
$$

In our illustrations, we consider a fund with 65 generations of which 45 generations are working and 20 generations are retired. Labor income is equal to unity during the working phase and does not change with time or age. The pension contribution $C_{g}(t)=0.2$ (i.e. $20 \%$ of income) at any time and for each working generation. We assume that all generations are of the same size. The fund dynamics are simulated for $T=200$ years.

We will illustrate our results for specific parameter values. Unless mentioned otherwise, the parameter values describing the pension fund are as follows. We assume that the pension fund invests $50 \%$ in stocks and hedges $50 \%$ of interest rate risk, i.e. the investment strategy is chosen such that $50 \%$ of collective interest rate risk is being hedged. For every year in retirement, we determine the amount of pension wealth withdrawn using a conversion factor which is based on the term structure of risk-free interest rates. In line with CPB (2020a, b), we assume that the allocation rule of the collective excess returns is as follows. It decreases linearly from $150 \%$ at age $22-35 \%$ at retirement age 67 and stays constant at $35 \%$ during retirement. Note that we scale the allocation rule by a constant such that the entire collective excess return is being allocated to the fund members. Finally, we choose the age-specific hedge returns such that the degree of interest rate hedging increases linearly from $25 \%$ at age $22-50 \%$ at retirement age 67 and stays constant at $50 \%$ during retirement.

Every period, $10 \%$ of the pension contribution is added to the solidarity reserve, with the restriction that the solidarity reserve cannot exceed $15 \%$ of total pension fund assets. If a levy of $10 \%$ is not feasible, we will determine the levy such that the solidarity reserve will be exactly equal to $15 \%$ of total pension fund assets. Furthermore, $10 \%$ of positive collective excess returns are added to the solidarity reserve. Again with the restriction that the solidarity reserve cannot exceed $15 \%$ of total pension fund assets. Inspired by the Dutch policy discussion (see CPB, 2020b), we consider two payout policies. In the first policy, every period $1 / 15$ th of the solidarity reserve is being paid out. The second policy assumes that the pension fund exclusively uses the solidarity reserve to provide a minimum replacement ratio of $50 \%$ for every retired generation, with the restriction that the solidarity reserve cannot become negative. If the fund is unable to provide minimum replacement ratios of $50 \%$, the entire solidarity reserve will be used to increase replacement ratios. Finally, the initial solidarity reserve is assumed to be $5 \%$ of total pension fund assets. We note that this initial solidarity reserve is chosen arbitrary and is not equal to the solidarity reserve that will arise after 200 years of simulation (i.e. the so-called steady state solidarity reserve). To compute the sensitivity of our results to the initial solidarity reserve, we perform the analysis for various starting values of the solidarity reserve.

We note that the design of the solidarity reserve includes various non-linear elements. Two examples are: excess returns will be added to the reserve only if they are positive and $10 \%$ of contributions will go to the reserve as long as the reserve is not larger than $15 \%$ of total pension fund assets. Figure 1 illustrates realizations of 


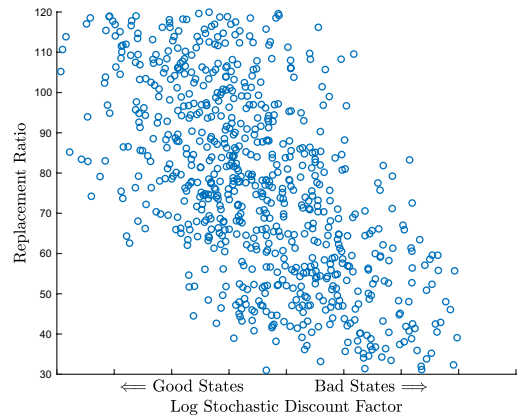

(a) Payout: 1/15th of Solidarity Reserve

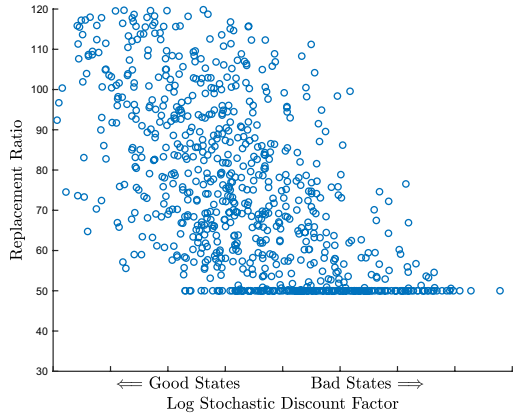

(b) Payout: Minimum Replacement Ratio of $50 \%$

Fig. 1 Realizations of replacement ratios. The figure illustrates realizations of replacement ratios at the age of retirement after 20 years of simulation. The parameter setting is described in this section

replacement ratios at the age of retirement after 20 years of simulation. We observe that the solidarity reserve is unable to impose a pronounced non-linear structure on pension outcomes in case the reserve pays out $1 / 15$ th every year. If the policy aims to ensure a minimum replacement ratio of $50 \%$, then we find a more pronounced non-linear structure on pension outcomes.

\subsection{Description of Financial Market}

The pension fund has access to three assets: a risk-free asset, a zero-coupon nominal bond with a fixed time to maturity and a risky stock. The return on the risk-free asset, which is the short-term interest rate, is given by $r(t)$. It satisfies the familiar Vasicek dynamics:

$$
r(t+1)=r(t)+\varphi(\bar{r}-r(t))+\sigma_{r} \epsilon_{r}(t+1) .
$$

Here, $\bar{r}$ denotes the expected long-run short-term interest rate, $\varphi \geq 0$ represents the degree of mean reversion in the short-term interest rate, $\sigma_{r} \geq 0$ models the interest rate volatility, and $\epsilon_{r}(t+1)$ is a standard normal random variable.

We denote the bond price and the stock price at time $t$ by $B(t)$ and $S(t)$, respectively. We represent the $\log$ bond return $r_{B}(t+1) \equiv \log B(t+1)-\log B(t)$ and the $\log$ stock return $r_{S}(t+1) \equiv \log S(t+1)-\log S(t)$ as follows: ${ }^{8}$

$$
\begin{aligned}
& r_{B}(t+1)=r(t)+\mu_{B}^{e}+\sigma_{B} \epsilon_{r}(t+1), \\
& r_{S}(t+1)=r(t)+\mu_{S}^{e}+\sigma_{S} \epsilon_{S}(t+1) .
\end{aligned}
$$

\footnotetext{
${ }^{8}$ Note that $\mu_{B}^{e}$ and $\sigma_{B}$ follow from the valuation of a contingent claim that pays 1 at the maturity date. See Backus et al. (1998) and Campbell and Viceira (2001) for the specification of $\mu_{B}^{e}$ and $\sigma_{B}$.
} 
Here, $\mu_{B}^{e} \geq 0$ and $\mu_{S}^{e} \geq 0$ denote the expected excess return on the log bond price and the $\log$ stock price, respectively, $\sigma_{B} \geq 0$ and $\sigma_{S} \geq 0$ model the log bond return volatility and the log stock return volatility, respectively, and $\epsilon_{S}(t+1)$ is a standard normal random variable. We denote the correlation coefficient between $\epsilon_{r}(t+1)$ and $\epsilon_{S}(t+1)$ by $\rho \in[-1,1]$.

The parameter values describing the financial market are as follows. We assume that the expected long-run short-term nominal interest rate, i.e. $\bar{r}$, is equal to $2 \%$. The initial short-term nominal interest rate, i.e. $r(0)$, is set equal to zero which is in line with the current low interest rate environment. The short-term interest rate volatility $\sigma_{r}$ equals $1 \%$. We assume that the half-time of the short-term interest rate, which uniquely identifies the mean reversion coefficient $\varphi$, equals 20 years. The interest rate risk premium is set equal to $7.5 \%$. These parameter values imply that the expected excess return on a 30-year zero-coupon nominal bond is $1.4 \%$ and its volatility is almost $19 \%$. $^{9}$ The stock return volatility $\sigma_{S}$ and the equity risk premium $\mu_{e}^{S}$ are assumed to be equal to $20 \%$ and $4 \%$, respectively. Finally, we assume that the interest rate shocks and the stock return shocks are uncorrelated (i.e. $\rho=0$ ).

\section{Solidarity Tax}

This section shows the results for the Solidarity Tax.

\subsection{Definition}

Intuitively, the Solidarity Tax measures for every 100 euro of pension contributions paid into the new pension contract, how many of these euros are channeled into the solidarity reserve either directly or at a later point in time. The Solidarity Tax is defined for working generations and is a percentage that lies between 0 and $100 \%$. More formally, the Solidarity Tax of working generation $g$ at time $t$, i.e. $\tau_{g}(t)$, is defined as follows:

$$
\tau_{g}(t)=\tau_{C}(t)+\sum_{h=1}^{G-g} \frac{V_{g}(t, h)}{C_{g}(t)},
$$

with $V_{g}(t, h)$ the value at time $t$ of the contribution to the solidarity reserve at time $t+h$. It is defined as follows:

$$
\begin{aligned}
V_{g}(t, h) \equiv & \mathbb{E}_{t}\left[\frac{m(t+h)}{m(t)}\right. \\
& \left.\times \tau_{r}(t+h) \bar{W}_{g+h}(t, t+h) x_{g+h}(t+h) \max \left(R_{W}^{e}(t+h)-1,0\right)\right] .
\end{aligned}
$$

\footnotetext{
${ }_{9}$ The parameters underlying the interest rate process are in line with Van Bilsen et al. (2020).
} 


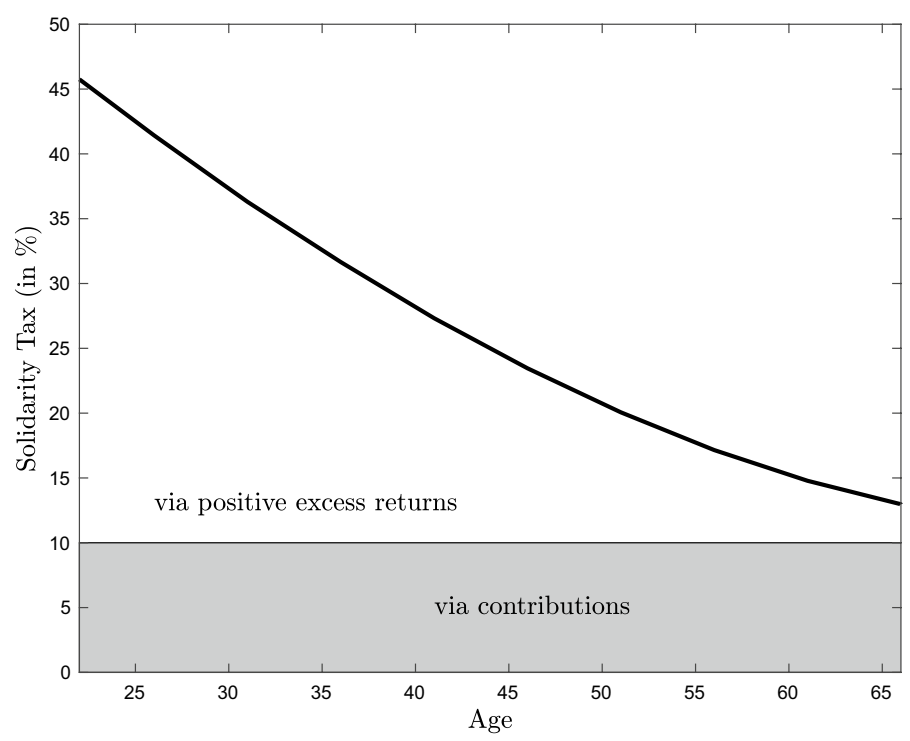

Fig. 2 Solidarity Tax. The figure shows for every working generation, the share of the pension contribution that goes into the solidarity reserve either directly or indirectly via future positive excess returns. The parameter setting is given in Sect. 2 . We assume that every period, $1 / 15$ th of the solidarity reserve is being paid out

Here, $m(t)$ denotes the stochastic discount factor at time $t$ and $\bar{W}_{g+h}(t, t+h)$ represents the part of $\bar{W}_{g+h}(t+h)$ (see (2.6)) that is associated with the pension contribution made at time $t$.

As can be seen in formula (3.1), the Solidarity Tax can be decomposed into two parts. The first part represents the direct transfers into the solidarity reserve which occur at the moment of saving, since a fraction of the pension contribution goes directly into the solidarity reserve. The second part represents transfers which occur in later years (thus: after the moment of saving), since a fraction of future positive collective excess returns will go into the solidarity reserve as well.

\subsection{Results}

Figure 2 illustrates the Solidarity Tax as a function of age for the first benchmark design. That is, in every period, $1 / 15$ th of the solidarity reserve is being paid out. The Solidarity Tax in Fig. 2 is shown in the form of a 'stacked area' chart, implying that the top solid line represents the Solidarity Tax, which is decomposed into two areas.

The gray area represents the direct transfers into the solidarity reserve which occur at the moment of saving, since a fraction of the pension contribution goes directly to the solidarity reserve. The gray area corresponds to the first term on the right-hand side of formula (3.1). In the benchmark situation, the fraction of contributions that goes directly into the solidarity reserve is $10 \%$ for all workers, and 
hence the gray area takes the form of a rectangular with a height of $10 \%$ for all working generations.

The area between the solid line and the gray area in Fig. 2 represents transfers which occur in later years (thus: after the moment of the savings are contributed into the new pension contract), because a fraction of future positive collective excess returns will go into the solidarity reserve as well. This area corresponds to the second term on the right-hand side of formula (3.1).

Figure 2 shows that the Solidarity Tax is higher than $10 \%$ for all working generations, and that it is highest for younger workers. The Solidarity Tax for younger workers is around $40 \%$ of their pension contributions. This means that for every 100 euro pension contribution, 40 euros will be transferred to the solidarity reserve either directly or later in time. There are two reasons that the Solidarity Tax of younger workers is higher than for older workers. First, the savings of younger workers are invested for a longer investment horizon in comparison to older workers. Second, the savings of younger workers are invested in riskier assets in comparison to older workers, implying that positive excess returns will be larger for younger workers. Hence, the savings of younger workers will generate higher positive excess returns over a longer investment horizon. This thus leads to a higher Solidarity Tax.

Table 1 illustrates the Solidarity Tax for different settings (see also "Appendix 2"). We have computed the Solidarity Tax for various values of the initial solidarity reserve. We observe that the initial solidarity reserve barely affects the Solidarity Tax as the initial solidarity reserve has a limited impact on how much workers will contribute to the reserve. Table 1 also shows that the term structure of interest rates, the age-specific hedge returns and the collective degree of interest rate hedging have limited impact on the Solidarity Tax. However, what matters is the collective investment strategy in stocks and the allocation rule of collective excess returns. Indeed, we note that the future collective excess returns and the allocation rule directly affect the second component (i.e. indirect transfers after the moment of savings) of the Solidarity Tax. The intuition is clear: the sizes of future collective excess returns and the exposure to future excess returns largely determine how much an individual will contribute to the solidarity reserve.

\subsection{Alternative Design}

So far we have assumed that part of a positive collective excess return goes into the solidarity reserve. This may lead to a significant Solidarity Tax; see Fig. 2. An alternative is that generations contribute only if the average past collective excess return is positive. The intuition behind this alternative measure is that a positive excess return in one single year may not be a desirable measure, because a positive excess return may be preceded by negative excess returns in previous years. Also, the alternative measure reduces transfers into the reserve in scenarios in which bad and good times alternate. In such scenarios, the alternative measure features limited transfers into the reserve as the average past returns can be moderate (while annual returns can be large). The idea behind the alternative measure is somewhat similar to the 
Table 1 Sensitivity of solidarity tax

\begin{tabular}{lllll}
\hline Setting & \multicolumn{2}{l}{ Age } & & \\
\cline { 2 - 5 } & 22 & 32 & 52 & 62 \\
\hline (a) Sensitivity with respect to initial solidarity reserve & & & \\
Initial Reserve $=1 \%$ & 44.70 & 35.49 & 19.83 & 14.69 \\
Initial Reserve $=7.5 \%$ & 46.42 & 36.84 & 20.22 & 14.84 \\
Initial Reserve $=10 \%$ & 47.07 & 37.37 & 20.37 & 14.90 \\
Initial Reserve $=14 \%$ & 46.46 & 37.03 & 19.93 & 14.55 \\
\hline Setting & Age & & & 60 \\
\cline { 2 - 5 }
\end{tabular}

(b) Sensitivity with respect to collective investment strategy

\begin{tabular}{lllll} 
Wealth Invested in Stock $=25 \%$ & 29.58 & 24.08 & 15.20 & 12.43 \\
Wealth Invested in Stock $=75 \%$ & 56.58 & 46.47 & 25.45 & 17.51 \\
Degree of Interest Rate Hedging $=25 \%$ & 45.83 & 36.71 & 20.47 & 14.94 \\
Degree of Interest Rate Hedging $=75 \%$ & 49.63 & 39.34 & 21.08 & 15.24 \\
\hline Setting & Age & & & 60 \\
\cline { 2 - 4 } & 30 & 40 & 50 & 60 \\
\hline
\end{tabular}

(c) Sensitivity with respect to allocation excess returns

\begin{tabular}{lllll} 
Allocation Excess Returns: 200-20-20 & 52.96 & 40.64 & 19.69 & 13.60 \\
Allocation Excess Returns: 75-50-50 & 39.03 & 33.16 & 21.57 & 16.53 \\
\hline Setting & Age & & & 60 \\
\cline { 2 - 5 } & 30 & 40 & 50 & 60 \\
\hline
\end{tabular}

(d) Sensitivity with respect to age-specific hedge returns

\begin{tabular}{lllll} 
Age-specific Hedge Returns: 0-100-100 & 47.66 & 37.16 & 20.44 & 14.99 \\
Age-specific Hedge Returns: 50-50-50 & 46.45 & 37.07 & 20.47 & 14.94 \\
\hline Setting & Age & & & \\
\cline { 2 - 5 } & 30 & 40 & 50 & 60 \\
\hline
\end{tabular}

(e) Sensitivity with respect to term structure of interest rates

Interest Rate $=0 \%$ for every Horizon $\quad 44.58 \quad 35.48 \quad 19.80 \quad 14.71$

The table shows for a number of ages, the share of the pension contribution that goes into the solidarity reserve either directly or indirectly via future positive excess returns (in \%). We compute the sensitivity with respect to the initial reserve (panel a), the collective investment strategy (panel b), the allocation rule of excess returns (panel c), the specification of age-specific hedge returns (panel d) and the term structure of interest rates (panel e). An allocation rule of 200-20-20 means that the allocation of excess returns decreases linearly from $200 \%$ at age $22-20 \%$ at retirement age 67 and stays constant at $20 \%$ during retirement. A specification of age-specific hedge returns of 0-100-100 means that the hedge returns are chosen such that the degree of interest rate hedging increases linearly from $0 \%$ at age $22-100 \%$ at retirement age 67 and stays constant at $100 \%$ during retirement. The parameter setting is given in Sect. 2. We assume that every period, $1 / 15$ th of the reserve is being paid out 


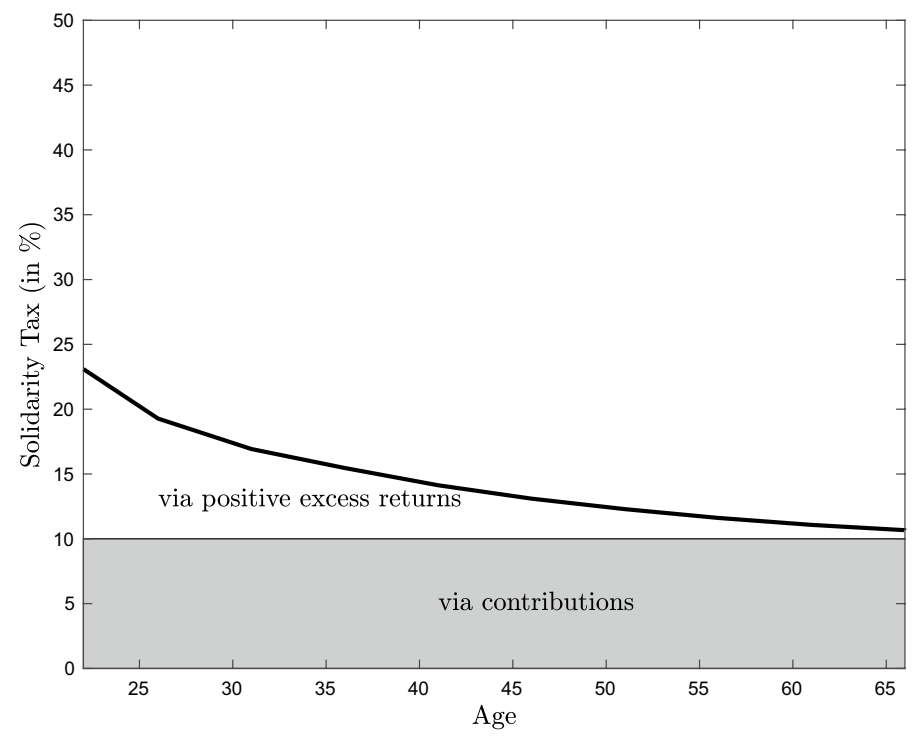

Fig. 3 Solidarity Tax in case of alternative design. The figure shows for every working generation, the share of the pension contribution that goes into the solidarity reserve either directly or indirectly via future positive excess returns. The parameter setting is given in Sect. 2. We assume that every period, $1 / 15$ th of the reserve is being paid out

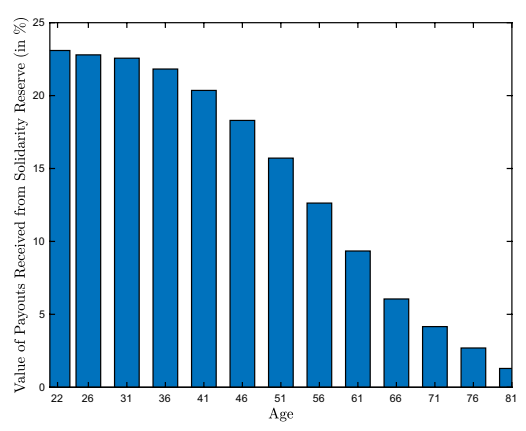

(a) Payout: 1/15th of Solidarity Reserve

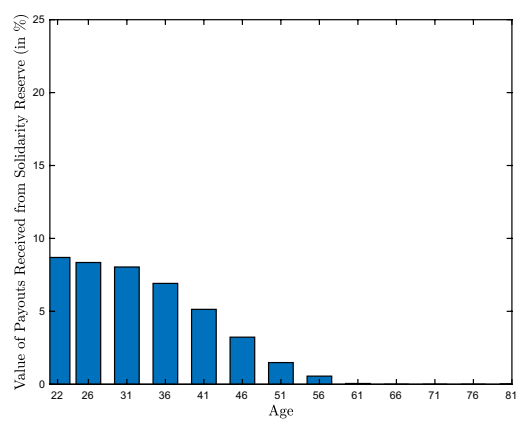

(b) Payout: Minimum Replacement Ratio of $50 \%$

Fig. 4 Value of payouts received from solidarity reserve. The figure shows for various generations the market value of the payouts received from the solidarity reserve expressed as percentage of total pension wealth. We define total pension wealth as the sum of accrued pension wealth and the discounted value of future pension contributions. The left panel assumes that every period, $1 / 15$ th of the solidarity reserve is being paid out. In the right panel, the pension fund uses the solidarity reserve to provide a minimum replacement ratio of $50 \%$ for every retired generation. The parameter setting is given in Sect. 2

concept of a 'high watermark' as applied in the literature on performance measurement, see e.g. Liang (1999).

Figure 3 shows the Solidarity Tax as a function of age, similar to Fig. 2, but now based on the alternative measure. The alternative measure substantially reduces the 
Solidarity Tax. Figure 3 shows that the alternative measure leads to a substantially lower Solidarity Tax. For young participants, aged 25, the Solidarity Tax equals approximately $20 \%$ instead of $40 \%$. For a 45 -year old worker, the Solidarity Tax is around $15 \%$ instead of $25 \%$. Hence, the alternative measure can be an effective way to reduce the Solidarity Tax on workers in case a pension fund aims to reduce the role of the solidarity reserve.

\section{Net Value Transfer}

The Solidarity Tax can be interpreted as an upper bound on the degree of intergenerational solidarity. However, members typically also receive payouts from the solidarity reserve. Figure 4 illustrates the market value of the payouts received from the solidarity reserve expressed as percentage of total pension wealth. ${ }^{10} \mathrm{We}$ observe that this value decreases with age. Indeed, the value of payouts received from the solidarity reserve is largest when young due to a long investment horizon. This section illustrates the so-called Net Value Transfer which considers both the contributions to the solidarity reserve and the payouts received from the solidarity reserve.

\subsection{Definition}

Intuitively, the Net Value Transfer measures how much money is transferred from one generation to other generations. Hence, the Net Value Transfer can be viewed as a pay-as-you-go aspect of the new pension contract. More specifically, it is equal to the difference between the ex-ante market value of all wealth paid into the solidarity reserve over the remaining life-cycle (either directly via a levy on pension contributions or indirectly via a levy on future positive excess returns) and the ex-ante market value of all wealth received from the solidarity reserve over the remaining lifecycle. A positive Net Value Transfer thus means that part of a generation's pension wealth goes to other generations. Formally, the Net Value Transfer of generation $g$ at time $t$, i.e. $N_{g}(t)$, is defined as follows:

$$
\begin{aligned}
N_{g}(t)= & \tau_{C}(t) C_{g}(t)+\sum_{h=1}^{G-g} \mathbb{E}_{t}\left[\frac { m ( t + h ) } { m ( t ) } \left\{\tau_{C}(t+h) C_{g+h}(t+h)\right.\right. \\
& \left.\left.+\tau_{r}(t+h) \bar{W}_{g+h}(t+h) x_{g+h}(t+h) \max \left(R_{W}^{e}(t+h)-1,0\right)\right\}\right] \\
& -\sum_{h=0}^{G-g} \mathbb{E}_{t}\left[\frac{m(t+h)}{m(t)} P_{g+h}^{*}(t+h)\right] .
\end{aligned}
$$

\footnotetext{
${ }^{10}$ Note that to compute the market value of payouts received from the solidarity reserve for a specific age, we need to specify the initial account value. We assume that the initial account value equals the median capital resulting from a defined contribution contract.
} 


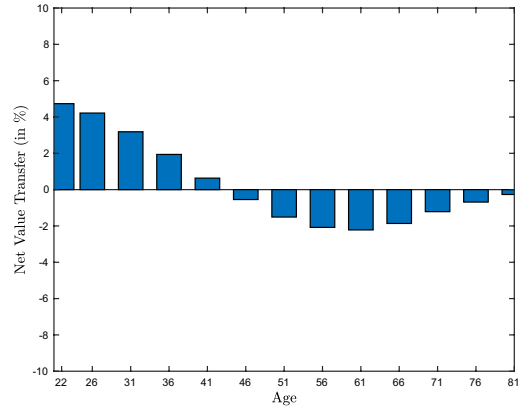

(a) Payout: 1/15th of Solidarity Reserve

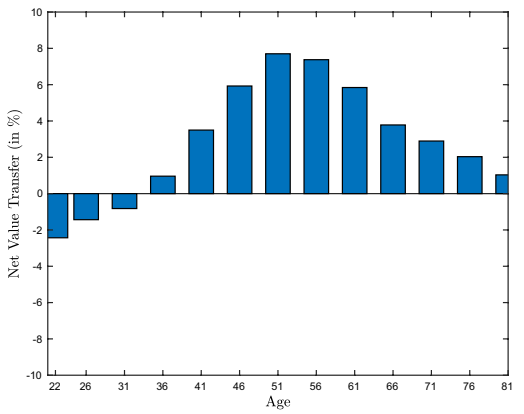

(b) Payout: Minimum Replacement Ratio of $50 \%$

Fig. 5 Net value transfer. The figure shows for various generations the share of total pension wealth that is being transferred to other generations. A positive Net Value Transfer thus means that part of a generation's pension wealth goes to other generations. We define total pension wealth as the sum of accrued pension wealth and the discounted value of future pension contributions. The left panel assumes that every period, 1/15th of the solidarity reserve is being paid out. In the right panel, the pension fund uses the solidarity reserve to provide a minimum replacement ratio of $50 \%$ for every retired generation. The parameter setting is given in Sect. 2

Here, $P_{g+h}^{*}(t+h)$ represents the total payout from the solidarity reserve to generation $g+h$ at time $t+h$ (see (6.11) in "Appendix 1"). As can be seen in formula (4.1), the Net Value Transfer can be decomposed into three parts. The first two parts represent contributions to the solidarity reserve (either directly via a levy on pension contributions or indirectly via a levy on future positive excess returns) and the last parts represents payouts received from the solidarity reserve.

\subsection{Results}

Figure 5 shows the results of the Net Value Transfer as a function of age for the two different payout policies as described in Sect. 2. The left panel shows the Net Value Transfers for the payout policy in which $1 / 15$ th of the solidarity reserve is being paid out annually. The right panel shows the Net Value Transfers for the payout policy in which the pension fund uses the solidarity reserve to provide a minimum replacement ratio of $50 \%$ for every retired generation. ${ }^{11}$

Figure 5 illustrates that the Net Value Transfers as a function of age is highly sensitive to the payout policy. The intergenerational effects are relatively modest in the policy shown in the left panel of Fig. 5, where the solidarity reserve increases or reduces the value of future pension income with at most $4 \%$. However, the intergenerational transfers are substantially larger, up to $8 \%$, and in opposite direction in the policy shown in the right panel of Fig. 5.

\footnotetext{
11 Note that to compute the Net Value Transfer for a specific age, we need to specify the initial account value. We assume that the initial account value equals the median capital resulting from a defined contribution contract.
} 
Table 2 Sensitivity of net value transfer

\begin{tabular}{|c|c|c|c|c|c|}
\hline \multirow[t]{2}{*}{ Setting } & \multirow[t]{2}{*}{ Payout policy } & \multicolumn{4}{|l|}{ Age } \\
\hline & & 30 & 40 & 50 & 60 \\
\hline \multicolumn{6}{|c|}{ Sensitivity with respect to initial solidarity reserve } \\
\hline Initial Reserve $=1 \%$ & $1 / 15$ th & 6.69 & 6.15 & 2.81 & 1.39 \\
\hline Initial Reserve $=1 \%$ & $\mathrm{MRR}>50 \%$ & 2.19 & 4.00 & 10.35 & 6.76 \\
\hline Initial Reserve $=14 \%$ & $1 / 15$ th & -0.25 & -4.78 & -13.13 & -11.87 \\
\hline Initial Reserve $=14 \%$ & $\mathrm{MRR}>50 \%$ & -12.92 & -12.61 & -3.63 & -0.47 \\
\hline \multirow[t]{2}{*}{ Setting } & \multirow[t]{2}{*}{ Payout policy } & \multicolumn{4}{|l|}{ Age } \\
\hline & & 30 & 40 & 50 & 60 \\
\hline \multicolumn{6}{|c|}{ Sensitivity with respect to term structure of interest rates } \\
\hline $\begin{array}{l}\text { Interest Rate }=0 \% \text { for } \\
\text { every Horizon }\end{array}$ & $1 / 15$ th & 5.39 & 3.85 & -1.02 & -2.10 \\
\hline $\begin{array}{l}\text { Interest Rate }=0 \% \text { for } \\
\text { every Horizon }\end{array}$ & MRR > 50\% & -4.39 & -5.71 & -0.00 & 3.66 \\
\hline
\end{tabular}

The table shows for a number of ages, the share of total pension wealth that is being transferred to other generations (in \%). A positive Net Value Transfer thus means that part of a generation's pension wealth goes to other generations. We define total pension wealth as the sum of accrued pension wealth and the discounted value of future pension contributions. We compute the sensitivity with respect to the initial solidarity reserve (panel a) and the term structure of interest rates (panel b). We consider two payout policies: a payout policy in which every period $1 / 15$ th of the solidarity reserve is being paid out and a payout policy in which the solidarity reserve aims at providing a minimum replacement ratio (MRR) of $50 \%$ for every retired generation. The parameter setting is given in Sect. 2

The policy shown on the left, in which $1 / 15$ th is paid out annually, results in the situation in which the Net Value Transfer is negative for generations older than 40 (in other words: these generations are better off from an ex-ante perspective), while it is positive for generations younger than 40 years (in other words: these generations are worse off from an ex-ante perspective). ${ }^{12}$ Hence, in terms of ex-ante market value, there is a value transfer from younger generations to older generations. The intuition behind this result is that the initial older generations have accumulated relatively high pension wealth and, because the initial reserve of $5 \%$ of pension fund assets, they receive relatively high transfers during their (short) remaining lifetime. This 'initial gift' to the initial old generations has to be financed by younger and future generations because intergenerational transfers are a zero-sum game in terms of ex-ante market value (see e.g. Ponds, 2003; Bovenberg \& Mehlkopf, 2014).

The reverse pattern is visible in the policy shown on the right, in which the solidarity reserve aims to ensure a minimum replacement ratio of 50\%. Under this policy, the Net Value Transfer is positive for all generations older than 40 (in other words: these generations are worse off from an ex-ante perspective), while it is negative for generations younger than 40 (in other words: these generations benefit from an ex-ante perspective). ${ }^{13}$ The intuition for this result is that the initial older

12 The Net Value Transfer is also positive for future generations, although this is not visible in the graph.

13 The Net Value Transfer is also negative for future generations, although this is not visible in the graph. 
generations start with a replacement ratio that is around $85 \%$ which is substantially higher than the minimum replacement ratio of $50 \%$. As a result, the payout policy of the solidarity reserve does not lead to payouts in the short run in most economic scenarios, because replacement ratios are well above the minimum target level. As a result, in most scenarios, the initial older generations contribute to the solidarity reserve (via the levy on excess returns) while they do not receive anything in return. Thus there is an 'initial loss' for the initial older generations. This 'initial loss' for the initial older generations benefits the initial younger generations and future generations because of the zero-sum game characteristic of intergenerational transfers. However, the direction of this intergenerational transfer is sensitive to the minimum replacement ratio applied in the policy. If a higher minimum replacement ratio would be used in the policy and a higher initial solidarity reserve, then the direction of intergenerational transfer could reverse. Hence, with a higher minimum replacement ratio and a higher initial solidarity reserve, there is an 'initial gift' (instead of an 'initial loss') for the initial retirees.

Table 2 shows that not only the right panel of Fig. 5 but also the left panel of Fig. 5 is sensitive to the initial size of the reserve (see also "Appendix 3"). The starting value of the solidarity reserve has a big impact on the sizes of the transfers between generations. Table 2 (see also "Appendix 3") also computes the Net Value Transfer for the case in which the term structure of interest rates is flat at $0 \%$. We note that in case the term structure of interest rate is $0 \%$, the implicit subsidy from young to old in a pension system with uniform contribution rates and uniform accrual rates - more or less - vanishes. However, this will not be the case here. Even if the interest rate is $0 \%$, there will be substantial transfers between generations caused by the specific design of the solidarity reserve. It seems that the interest rate has limited impact on the sizes of these transfers.

\section{Conclusion}

Our analysis calculates the redistributive effects of the policy design for the solidarity reserve as it has been put forward in CPB (2020a, b), which is the research conducted on behalf of the government. In other words: we simply consider the policy designs that the government had in mind when designing the draft legislation, without being concerned with the question to what extent these policy designs are optimal or not. We do, however, believe that our paper provides valuable insights in two respects.

First, we believe that the two measures proposed in this paper, the Solidarity Tax and the Net Value Transfer, are useful measures to assess the intergenerational transfers induced by the solidarity reserve. The Solidarity Tax measures to what extent the contract is 'personal' in nature and to what extent it is 'collective', and this can be a relevant measure for policy makers who have certain objectives in this respect. For example, a pension fund that is characterized by relatively many job switches among its working participants (e.g. due to a high degree of 'expat workers' who are typically expected to work for the company only for a few years) may prefer a more individual design of the solidarity reserve. Indeed, a more individual design 
may reduce labor supply distortions induced by substantial value transfers between generations. After all, it may be more difficult to get new hires if the company's pension fund has a pension scheme with a solidarity reserve which does not work in their favor.

Second, the quantitative results of our paper shed light into the potential redistributive effects of the solidarity reserve if pension funds will chose an implementation that is similar to the ones put forward in CPB (2020a, b). Our results imply that the solidarity reserve can introduce 'implicit assets' or 'implicit debts' in the pension contract. In the case of 'implicit assets' there is a value transfer resulting from an 'initial loss' for initial older generations which benefits initial younger and future generations as a result of the zero-sum game. In the case of 'implicit debts' there is an 'initial gift' for the initial older generations, which has to be financed by the initial younger and future generations. In this latter case, the pension system features a pay-as-you-go element. The possibility of a pay-as-you-go element via the solidarity reserve is relevant for policy makers. As mentioned in the introduction, the pension bill devotes a lot of attention towards the removal of a pay-as-you-go element in the current pension contracts resulting from the so-called uniform contributions and uniform accrual system. Given the explicit aim of the policy reform to remove a pay-as-you-go element, it is remarkable that the pension bill allows for the introduction of a new pay-as-you-go element via the solidarity reserve. Our policy recommendation to pension funds is to make explicit whether or not there is a pay-as-yougo element via the solidarity reserve, and if so to assess whether this is desirable.

We see a few important avenues for future research. First, a limitation of our research is that we only consider a few specific designs of the solidarity reserve. It may be worth investigating to compute the results for a number of alternative designs. More generally, the analysis could be extended towards a modeling framework in which the design of the solidarity reserve is optimized with respect to a certain objective function (possibly also subject to a constraint that limits the size of redistributive transfers). Second, the analysis can be extended to a situation which accounts for labor supply effects. These effects may be endogenously determined by the size of the Net Value Transfer which affects the decisions for workers regarding labor supply and/or labor mobility. Finally, a third avenue for future research is to extend the analysis for the transfers between generations that are the result of inflation risk.

\section{Appendix 1: Design of the New Pension Contract: A Step-by-Step Approach}

This appendix describes step-by-step how we implement the new pension contract. Collective pension wealth at time $t$ is denoted by $W(t)$. The solidarity reserve at time $t$ is represented by the variable $S(t)$. It is not included in $W(t)$. Hence, total pension fund assets are equal to $W(t)+S(t)$. We assume that our pension fund consists of $G$ generations. We use the index $g \in\{1, \ldots, G\}$ to refer to generation $g$, where 
$g=1$ denotes the youngest generation and $g=G$ represents the oldest generation. We denote the pension wealth level of generation $g$ at time $t$ by $W_{g}(t)$. By definition,

$$
W(t)=\sum_{g=1}^{G} W_{g}(t) .
$$

In what follows, we abstract away from inflation risk, longevity risk and mortality risk.

\section{Contributions}

In the first step, generations pay a pension contribution. As a result, the pension wealth level of generation $g$ will increase by $\left(1-\tau_{C}(t)\right) C_{g}(t)$. Here, $C_{g}(t)$ denotes the pension contribution of generation $g$ at time $t$ and $\tau_{C}(t) \geq 0$ models the share of the pension contribution that goes into the solidarity reserve. ${ }^{14}$ Hence, the new pension wealth level of generation $g$, i.e. $\widetilde{W}_{g}(t)$, will be

$$
\widetilde{W}_{g}(t)=W_{g}(t)+\left(1-\tau_{C}(t)\right) C_{g}(t) .
$$

Note that the new pension wealth level of the youngest generation, i.e. $\widetilde{W}_{1}(t)$, is equal to $\left(1-\tau_{C}(t)\right) C_{1}(t)$ as $W_{1}(t)=0$ by construction. Furthermore, we note that retired generations do not pay a pension contribution (i.e. $C_{g}(t)=0$ for all retired generations).

New collective pension wealth and the new solidarity reserve are given by

$$
\begin{gathered}
\widetilde{W}(t)=\sum_{g=1}^{G} \widetilde{W}_{g}(t)=\sum_{g=1}^{G} W_{g}(t)+\left(1-\tau_{C}(t)\right) \sum_{g=1}^{G} C_{g}(t), \\
\tilde{S}(t)=S(t)+\tau_{C}(t) \sum_{g=1}^{G} C_{g}(t) .
\end{gathered}
$$

Total pension fund assets $W(t)+S(t)$ thus increase by total contributions $\sum_{g=1}^{G} C_{g}(t)$.

\section{Payouts}

In the second step, generations receive two payouts: a pension benefit (which is used for consumption) and a payout from the solidarity reserve. Let us denote by $B_{g}(t)$ and $P_{g}(t)$ the pension benefit of generation $g$ at time $t$ and the payout generation $g$ will receive from the solidarity reserve at time $t$, respectively. A working generation does not receive a pension benefit, so that $B_{g}(t)=0$ for all working generations. We find that the new pension wealth level of generation $g$, i.e. $\widetilde{W}_{g}(t)$, is given by

\footnotetext{
${ }^{14}$ We determine $\tau_{C}(t)$ always in such a way that the solidarity reserve does not exceed $15 \%$ of total pension fund assets.
} 


$$
\widetilde{W}_{g}(t)=\widetilde{W}_{g}(t)+P_{g}(t)-B_{g}(t) .
$$

We assume that the oldest generation consumes all remaining pension wealth, i.e. $B_{G}(t)=\widetilde{W}_{G}(t)+P_{G}(t)$.

New collective pension wealth and the new solidarity reserve are given by

$$
\begin{gathered}
\widetilde{W}(t)=\sum_{g=1}^{G} \widetilde{W}_{g}(t), \\
\check{S}(t)=S(t)-\sum_{g=1}^{G} P_{g}(t) .
\end{gathered}
$$

\section{Additional Payouts}

In the third step, generations may receive an additional payout. Since the payments of pension benefits cause total pension fund assets to decrease, the solidarity reserve can, in principle, exceed $15 \%$ of total pension fund assets, which is not allowed. If the solidarity reserve exceeds $15 \%$ of pension fund assets, we assume that generations will receive an additional immediate payout from the solidarity reserve (which is transferred to one's personal pension wealth) such that the restriction is met again. We find that the new pension wealth level of generation $g$, i.e. $W_{g}^{*}(t)$, is given by

$$
W_{g}^{*}(t)=\breve{W}_{g}(t)+\check{\alpha}_{g}(t) \max (\breve{S}(t)-15 \% \times\{\breve{W}(t)+\breve{S}(t)\}, 0),
$$

where the value weight $\check{\alpha}_{g}(t)$ is defined as follows:

$$
\check{\alpha}_{g}(t) \equiv \frac{\widetilde{W}_{g}(t)}{\widetilde{W}(t)} .
$$

We directly observe from (6.10) that generations will receive an additional immediate payout only if the solidarity reserve $\breve{S}(t)$ is larger than $15 \%$ of total pension fund assets $\breve{W}(t)+\breve{S}(t)$. By substituting (6.5) into (6.10), we find

$$
W_{g}^{*}(t)=\widetilde{W}_{g}(t)+P_{g}^{*}(t)-B_{g}(t),
$$

where

$$
P_{g}^{*}(t) \equiv P_{g}(t)+\check{\alpha}_{g}(t) \max (\breve{S}(t)-15 \% \times\{\breve{W}(t)+\check{S}(t)\}, 0)
$$

represents the total payout generation $g$ receives from the solidarity reserve. The first part on the right-hand side of (6.11) is specified by the pension fund board, while the second part on the right-hand side of (6.11) follows from a restriction imposed by the new contract.

Note that new collective pension wealth and the new solidarity reserve are given by 


$$
\begin{gathered}
W^{*}(t)=\sum_{g=1}^{G} W_{g}^{*}(t), \\
S^{*}(t)=\min (\check{S}(t), 15 \% \times\{\widetilde{W}(t)+\check{S}(t)\}) .
\end{gathered}
$$

\section{Investment of Collective Pension Wealth and Solidarity Reserve}

In the fourth step, the collective pension wealth level $W^{*}(t)$ and the solidarity reserve $S^{*}(t)$ are invested in the financial market. We assume that at any any time $t \in\{0,1, \ldots, T\}$, the pension fund has access to three assets: a risk-free asset, a zerocoupon nominal bond with a fixed time to maturity and a risky stock. We find that new collective pension wealth and the new solidarity reserve are given by

$$
\begin{gathered}
\widehat{W}(t+1)=W^{*}(t) R_{W}(t+1), \\
\widehat{S}(t+1)=S^{*}(t) R_{W}(t+1),
\end{gathered}
$$

where $R_{W}(t+1)$ denotes the gross return:

$$
R_{W}(t+1)=\pi_{B}(t) R_{B}(t+1)+\pi_{S}(t) R_{S}(t+1)+\left(1-\pi_{B}(t)-\pi_{S}(t)\right) e^{r(t)},
$$

with $R_{B}(t+1)$ and $R_{S}(t+1)$ the gross return on the bond price and the stock price, respectively, $r(t)$ the risk-free interest rate, and $\pi_{B}(t)$ and $\pi_{S}(t)$ the share of collective pension wealth invested in the bond and the stock, respectively. Note that (6.15) implies that the pension fund invests the solidarity reserve $S^{*}(t)$ in a similar fashion as it invests collective pension wealth $W^{*}(t)$. Also note that because of this assumption and the fact that the old solidarity reserve $S^{*}(t)$ is, by construction, smaller than $15 \%$ of total pension fund assets, the new solidarity reserve $\widehat{S}(t+1)$ is guaranteed to be smaller than $15 \%$ of total pension fund assets as well.

\section{Age-Specific Hedge Returns}

In the next step, the pension wealth level of generation $g$ will accrue a hedge return $H_{g}(t+1)$. Hence, the new pension wealth level of generation $g$ is given by

$$
\bar{W}_{g+1}(t+1)=W_{g}^{*}(t) H_{g}(t+1) \text {. }
$$

The hedge return $H_{g}(t+1)$ depends on the desired degree of protection against interest rate risk. We note that the actual degree of interest rate hedging typically differs from the desired degree of interest rate hedging, as part of collective interest rate risk can be transferred to individual pension wealth levels via the allocation rule of collective excess returns.

We now define the excess gross return on collective pension wealth, i.e. $R_{W}^{e}(t+1)$. It is defined as follows: 


$$
R_{W}^{e}(t+1) \equiv \frac{\widehat{W}(t+1)}{\sum_{g=1}^{G-1} \bar{W}_{g+1}(t+1)}
$$

Equation (6.18) implies that

$$
\sum_{g=1}^{G-1} \bar{W}_{g+1}(t+1) R_{W}^{e}(t+1)=\widehat{W}(t+1)
$$

\section{Allocation of Excess Return}

Not only the the solidarity reserve but also the allocation of the collective excess return plays an important role in the new pension contract. The new solidarity reserve, i.e. $S(t+1)$, will be

$$
S(t+1)=\widehat{S}(t+1)+\tau_{r}(t+1) \max \left(R_{W}^{e}(t+1)-1,0\right) \sum_{g=1}^{G-1} \bar{W}_{g+1}(t+1) .
$$

Here, $\tau_{r}(t+1) \geq 0$ models the share of pension wealth that goes into the solidarity reserve. ${ }^{15}$ It follows immediately from (6.20) that if $R_{W}^{e}(t+1) \leq 1$, $S(t+1)=\widehat{S}(t+1)$, so that no new money is added to the solidarity reserve. The new collective pension wealth level, i.e. $W(t+1)$, is given by

$$
W(t+1)=\sum_{g=1}^{G-1} \bar{W}_{g+1}(t+1)\left[R_{W}^{e}(t+1)-\tau_{r}(t+1) \max \left(R_{W}^{e}(t+1)-1,0\right)\right] .
$$

We observe from (6.21) that if $R_{W}^{e}(t+1) \leq 1, W(t+1)=\widehat{W}(t+1)$.

Finally, the new pension contract allocates the excess return across pension wealth levels $\bar{W}_{g+1}(t+1)$, with $g \in\{1, \ldots, G-1\}$. Let us define $x_{g+1}(t+1)$ the part of the excess return that is allocated to $\bar{W}_{g+1}(t+1)$. It now follows that the new pension wealth level of generation $g+1$, i.e. $W_{g+1}(t+1)$, is given by

$$
\begin{aligned}
W_{g+1}(t+1)= & \bar{W}_{g+1}(t+1)\left[1+x_{g+1}(t+1)\left(R_{W}^{e}(t+1)-1\right)\right. \\
& \left.-\tau_{r}(t+1) x_{g+1}(t+1) \max \left(R_{W}^{e}(t+1)-1,0\right)\right] .
\end{aligned}
$$

From (6.21), (6.22) and the condition $W(t+1)=\sum_{g=1}^{G-1} W_{g+1}(t+1)$, we find that

$$
\sum_{g=1}^{G-1} \bar{\alpha}_{g+1}(t+1) x_{g+1}(t+1)=1
$$

where the value weight $\bar{\alpha}_{g+1}(t+1)$ is defined as follows:

\footnotetext{
${ }^{15}$ We determine $\tau_{r}(t+1)$ always in such a way that the solidarity reserve does not exceed $15 \%$ of total pension fund assets.
} 


$$
\bar{\alpha}_{g+1}(t+1) \equiv \frac{\bar{W}_{g+1}(t+1)}{\sum_{g=1}^{G-1} \bar{W}_{g+1}(t+1)} .
$$

Intuitively, condition (6.23) implies that the collective excess return is fully allocated.

The description of the new pension contract is now completed.

\section{Appendix 2: Sensitivity of Solidarity Tax}

This appendix explores the sensitivity of the Solidarity Tax with respect to the initial solidarity reserve, the collective investment strategy, the allocation rule of the collective excess returns, the age-specific hedge returns, and the term structure of interest rates (Figs. 6, 7, 8, 9, 10, 11).

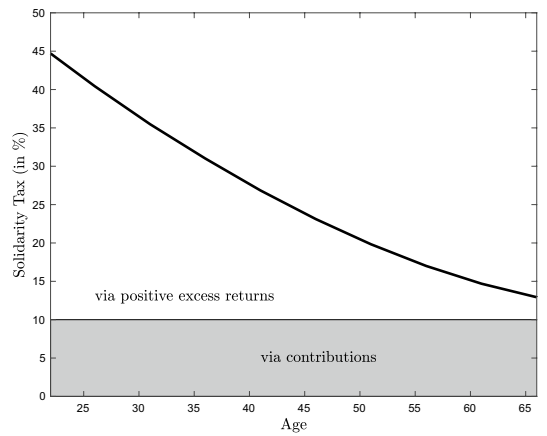

(a) Initial Solidarity Reserve $=1 \%$

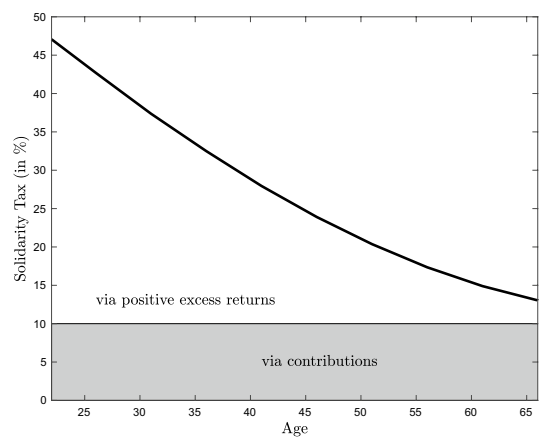

(c) Initial Solidarity Reserve $=10 \%$

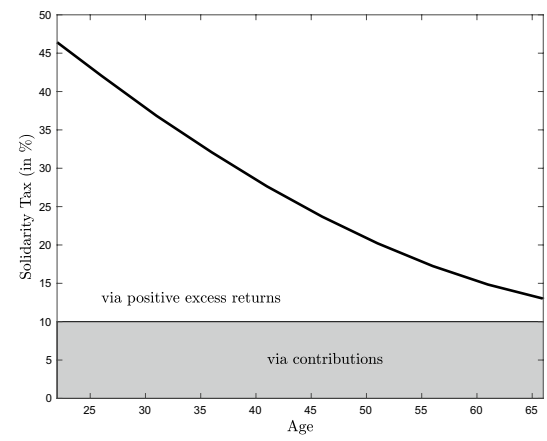

(b) Initial Solidarity Reserve $=7.5 \%$

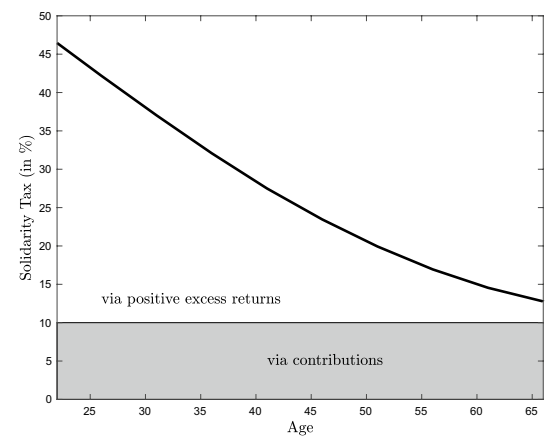

(d) Initial Solidarity Reserve $=14 \%$

Fig. 6 Sensitivity of Solidarity Tax with respect to initial solidarity reserve. The figure shows for every working generation, the share of the pension contribution that goes into the solidarity reserve either directly or indirectly via future positive excess returns. The parameter setting is given in Sect. 2. We assume that every period, $1 / 15$ th of the solidarity reserve is being paid out 


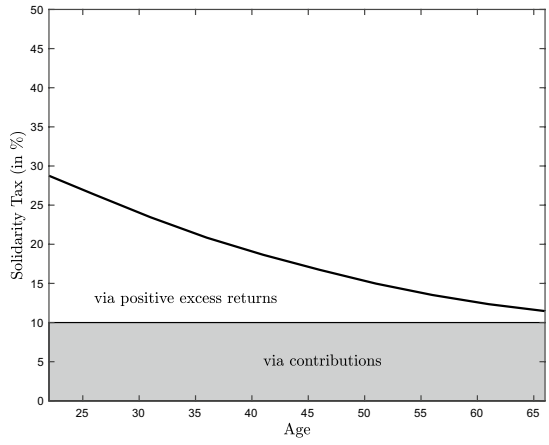

(a) Share Invested in Stock $=25 \%$

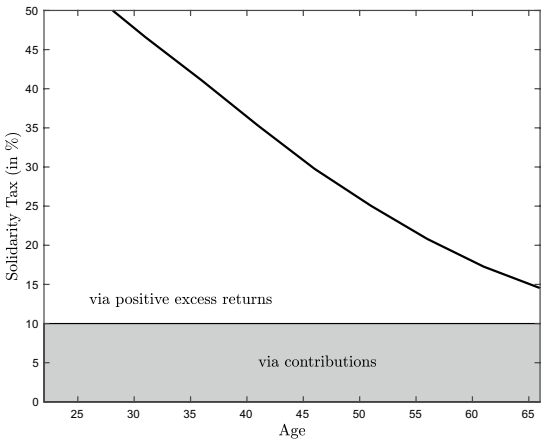

(b) Share Invested in Stock $=75 \%$

Fig. 7 Sensitivity of Solidarity Tax with respect to collective pension wealth invested in stock. The figure shows for every working generation, the share of the pension contribution that goes into the solidarity reserve either directly or indirectly via future positive excess returns. The parameter setting is given in Sect. 2. We assume that at the end of every period, $1 / 15$ th of the solidarity reserve is being paid out

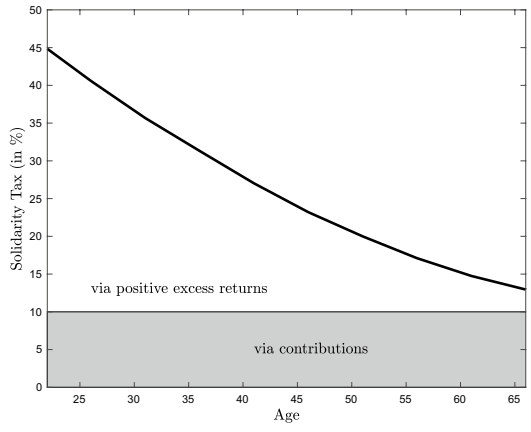

(a) Degree of Interest Rate Hedging $=25 \%$

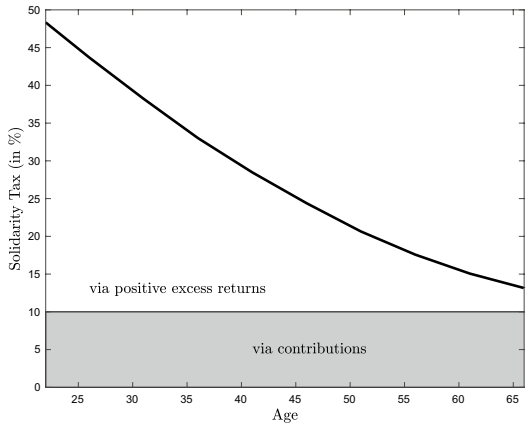

(b) Degree of Interest Rate Hedging $=75 \%$

Fig. 8 Sensitivity of Solidarity Tax with respect to collective degree of interest rate hedging. The figure shows for every working generation, the share of the pension contribution that goes into the solidarity reserve either directly or indirectly via future positive excess returns. The parameter setting is given in Sect. 2. We assume that every period, $1 / 15$ th of the solidarity reserve is being paid out 


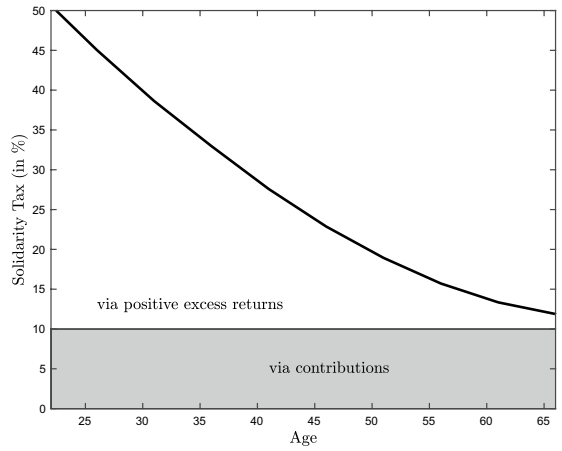

(a) $200-20-20$

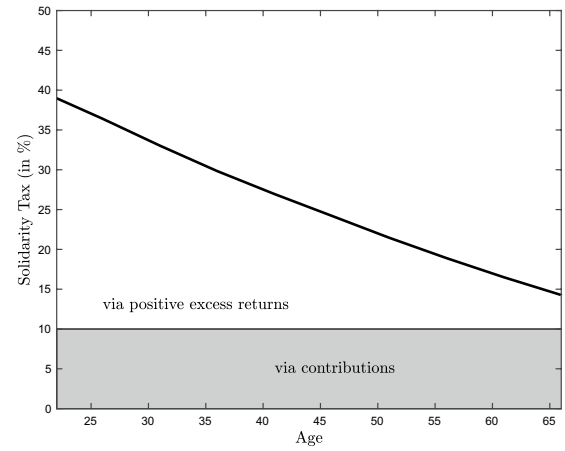

(b) $75-50-50$

Fig. 9 Sensitivity of Solidarity Tax with respect to the allocation rule of collective excess returns. The figure shows for every working generation, the share of the pension contribution that goes into the solidarity reserve either directly or indirectly via future positive excess returns. The left panel considers the allocation rule 200-20-20: it decreases linearly from 200\% at age 22 to $20 \%$ at retirement age 67 and stays constant at $20 \%$ during retirement. In the right panel, we assume the allocation rule $75-50-50$. The parameter setting is given in Sect. 2. We assume that every period, 1/15th of the solidarity reserve is being paid out

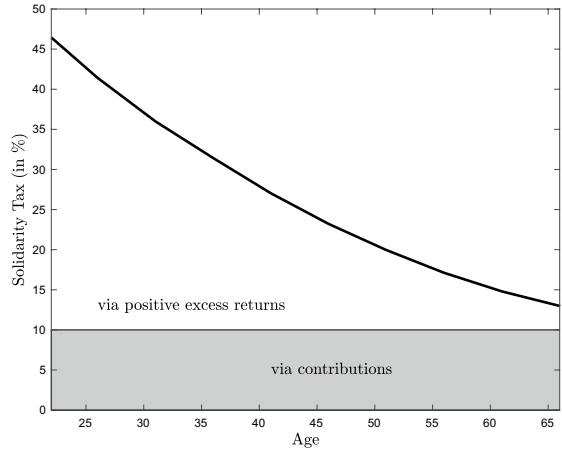

(a) $0-100-100$

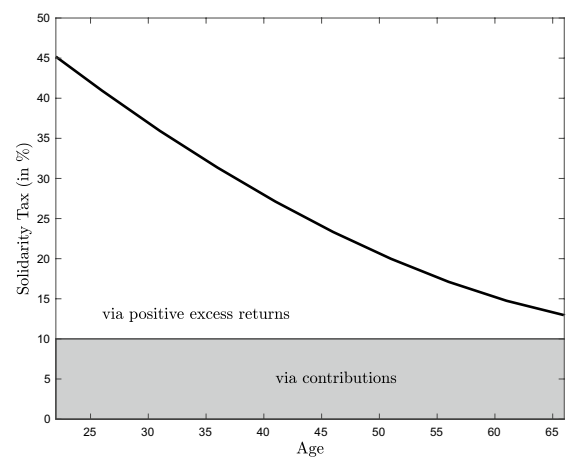

(b) $50-50-50$

Fig. 10 Sensitivity of Solidarity Tax with respect to age-specific hedge returns. The figure shows for every working generation, the share of the pension contribution that goes into the solidarity reserve either directly or indirectly via future positive excess returns. The left panel assumes that the hedge returns are chosen such that the degree of interest rate hedging increases linearly from $0 \%$ at age 22 to $100 \%$ at retirement age 67 and stays constant at $100 \%$ during retirement. In the right panel, we assume that the degree of interest rate hedging is constant at $50 \%$ during both the working phase and the retirement phase. The parameter setting is given in Sect. 2. We assume that every period, 1/15th of the solidarity reserve is being paid out 


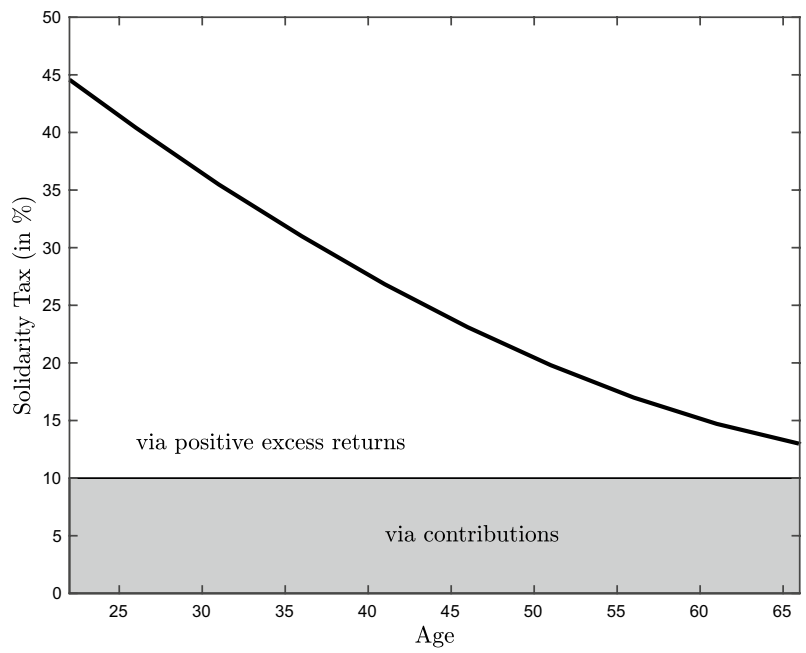

Fig. 11 Sensitivity of Solidarity Tax with respect to term structure of interest rates. The figure shows for every working generation, the share of the pension contribution that goes into the solidarity reserve either directly or indirectly via future positive excess returns. We assume that the term structure of interest rates is flat at $0 \%$. The parameter setting is given in Sect. 2. We assume that every period, $1 / 15$ th of the solidarity reserve is being paid out 


\section{Appendix 3: Sensitivity of Net Value Transfer}

This appendix explores the sensitivity of the Net Value Transfer with respect to the size of the initial solidarity reserve (Figs. 12, 13).

Payout Policy: 1/15th of Solidarity Reserve

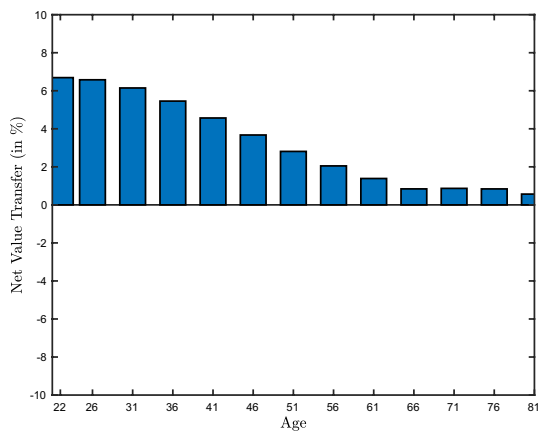

(a) Initial Solidarity Reserve $=1 \%$

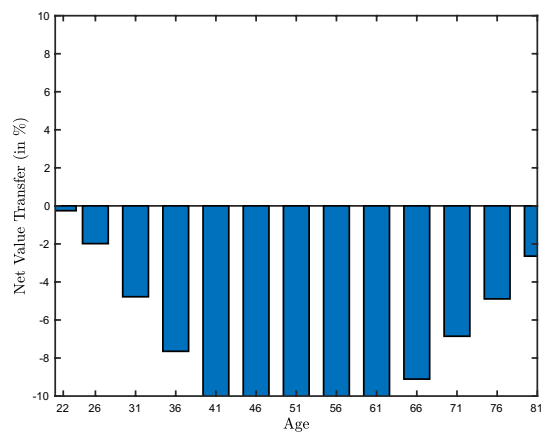

(b) Initial Solidarity Reserve $=14 \% \mathrm{tt}$

Payout Policy: Minimum Replacement Ratio of 50\%

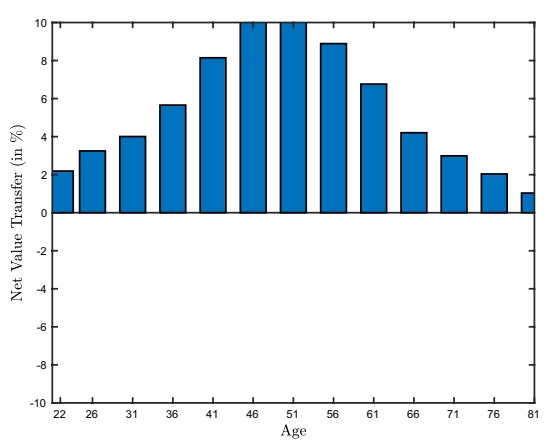

(c) Initial Solidarity Reserve $=1 \%$

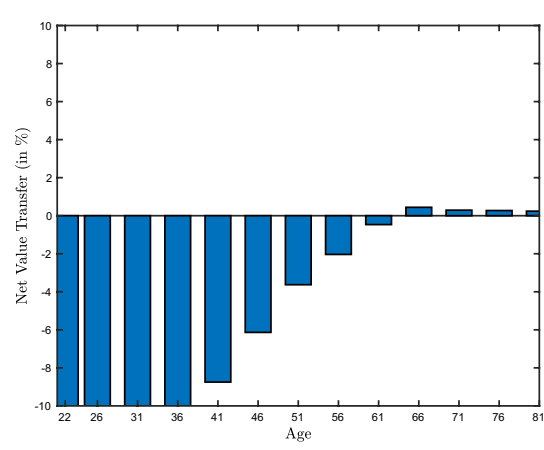

(d) Initial Solidarity Reserve $=14 \%$

Fig. 12 Sensitivity of net value transfer with respect to initial solidarity reserve. The figure shows for various generations the share of total pension wealth that is being transferred to other generations. A positive Net Value Transfer thus means that part of a generation's pension wealth goes to other generations. We define total pension wealth as the sum of accrued pension wealth and the discounted value of future pension contributions. The parameter setting is given in Sect. 2 


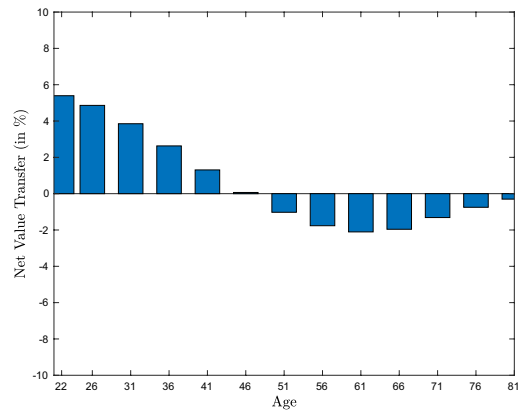

(a) Payout: 1/15th of Solidarity Reserve

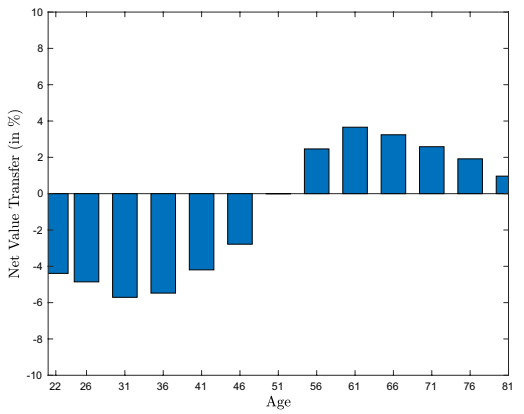

(b) Payout: Minimum Replacement Ratio of $50 \%$

Fig. 13 Sensitivity of Solidarity Tax with respect to term structure of interest rates. The figure shows for various generations the share of total pension wealth that is being transferred to other generations. A positive Net Value Transfer thus means that part of a generation's pension wealth goes to other generations. We define total pension wealth as the sum of accrued pension wealth and the discounted value of future pension contributions. We assume that the term structure of interest rates is flat at $0 \%$. The parameter setting is given in Sect. 2

Acknowledgements The research of Van Bilsen and Mehlkopf is financially supported by Instituut Gak.

Open Access This article is licensed under a Creative Commons Attribution 4.0 International License, which permits use, sharing, adaptation, distribution and reproduction in any medium or format, as long as you give appropriate credit to the original author(s) and the source, provide a link to the Creative Commons licence, and indicate if changes were made. The images or other third party material in this article are included in the article's Creative Commons licence, unless indicated otherwise in a credit line to the material. If material is not included in the article's Creative Commons licence and your intended use is not permitted by statutory regulation or exceeds the permitted use, you will need to obtain permission directly from the copyright holder. To view a copy of this licence, visit http://creativecommons.org/licen ses/by/4.0/.

\section{References}

Auerbach, A., Gokhale, J., \& Kotlikoff, L. (1991). Generational accounts: A meaningful alternative to deficit accounting. In D. Bradford (Ed.), Tax policy and the Economy (vol. 5, p. 55).

Backus, D., Foresi, S., \& Telmer, C. (1998). Discrete-time models of bond pricing. NBER Working Paper 6736.

Ball, L., \& Mankiw, N. G. (2007). Intergenerational risk sharing in the spirit of Arrow, Debreu, and Rawls, with applications to social security design. Journal of Political Economy, 115, 523-547.

Bovenberg, A. L., Mehlkopf, R. J., \& Nijman, Th. E. (2016). The promise of defined-ambition plans: Lessons for the United States. In O. S. Mitchell \& R. Shea (Eds.), Reimagining pensions: The next 40 years (pp. 215-246). Oxford: Oxford University Press.

Bovenberg, A. L., \& Mehlkopf, R. J. (2014). Optimal design of funded pension schemes. Annual Review of Economics, 6, 445-474.

Bovenberg, A. L., \& Nijman, T. E. (2018). New Dutch pension contracts and lessons for other countries. Journal of Pension Economics and Finance, 18(3), 331-346.

Campbell, J. Y., \& Viceira, L. M. (2001). Who should buy long-term bonds? American Economic Review, 91, 99-127. 
CPB. (2020a). Nieuwe Pensioenregels: Effecten en Opties van het Doorontwikkelde Contract en een Overgang naar een Vlak Premiepercentage, $C P B$ Notitie.

CPB. (2020b). Het Doorontwikkelde Contract: Uitdeel- en Vulopties voor de Solidariteitsreserve, $C P B$ Achtergronddocument.

Draper, N., van Ewijk, C., Lever, M., \& Mehlkopf, R. J. (2014). Stochastic generational accounting applied to reforms of Dutch occupational pensions. De Economist, 162, 287-304.

Gollier, C. (2008). Intergenerational risk sharing and risk-taking of a pension fund. Journal of Public Economics, 92, 1463-1485.

Gordon, R., \& Varian, H. (1988). Intergenerational risk sharing. Journal of Public Economics, 37, $185-202$.

Grosen, A., \& Jørgensen, P. L. (1988). Fair valuation of life insurance liabilities: The impact of interest rate guarantees, surrender options, and bonus policies. Insurance: Mathematics and Economics, 26, 37-57.

Kotlikoff, L. (1992). Generational accounting. New York: Free Press.

Liang, B. (1999). On the performance of hedge funds. Financial Analysts Journal, 55(4), 72-85.

Metselaar, L., Zwaneveld, P., \& van Ewijk, C. (2022). Reforming occupational pensions in the Netherlands: Contract and intergenerational aspects. XXX-XXX: De Economist XX.

Ponds, E. (2003). Pension funds and value-based generational accounting. Journal of Pension Economics and Finance, 2(3), 295-325.

van Bilsen, S., Boelaars, I., \& Bovenberg, A. L. (2020). The duration puzzle in life-cycle investment. Review of Finance, 24(6), 1271-1311.

Bilsen van, S., Mehlkopf, R., \& Pelsser, A. (2021). De voordelen van de solidariteitsreserve ontrafeld. Netspar Design Paper.

Werker, B., \& Muns, S. (2022). Pareto-Efficient Pension Risk Allocation. XX, XXX-XXX: De Economist.

Publisher's Note Springer Nature remains neutral with regard to jurisdictional claims in published maps and institutional affiliations. 